\title{
Dynamic Voltage Restorer With an Improved Strategy to Voltage Sag Compensation and Energy Self-Recovery
}

\author{
Chunming Tu, Qi Guo, Fei Jiang, Cheng Chen, Xiaoyun Li, Fan Xiao, and Jiayuan Gao
}

\begin{abstract}
In this paper, an improved control scheme is proposed to improve the voltage quality of sensitive loads using dynamic voltage restorer. The existing control strategies either put emphasis on the optimal control during steady operation stage of compensation or correct the phase angle jump in the initial stage of compensation. In current researches, the impact of phase jump characteristic of voltage sag on the load side after voltage sag recoveries is widely ignored, further, there are still drawbacks in existing energy self-recovery strategies of DVR. Therefore, to improve the overall voltage compensation time while correcting the phase jump and accelerate the energy recovery of dc link side, this paper aims to 1) Propose the strategies to minimum active power consumption during voltage compensation stage and maximum active power absorption during energy self-recovery stage. 2) Deliver smooth transition in dynamic process to ensure the flexible switching between two stages. Theoretical analysis of proposed strategy is been validated through simulation and experimental results.
\end{abstract}

Index Terms-Dynamic voltage restorer, phase jump, selfrecovery, smooth transition, voltage sag.

\begin{tabular}{ll} 
& \multicolumn{1}{c}{ NomenCLATURE } \\
$U_{\mathrm{S}}$ & Grid voltage. \\
$U_{\mathrm{S}}^{\prime}$ & Grid voltage after the sag. \\
$U_{\text {presag }}$ & Grid voltage before the sag. \\
$U_{\mathrm{L}}$ & load voltage. \\
$U_{\mathrm{L}}^{\prime}$ & load voltage after the sag. \\
$U_{\mathrm{Lref}}$ & Reference load voltage. \\
$U_{\mathrm{DVR}}$ & Injected voltage in compensation stage.
\end{tabular}

Manuscript received May 29, 2019. This work was supported by the General Programs of National Natural Science Foundation of China (51707014), (51577055). This paper was presented in part at the 2018 IEEE International Power Electronics and Application Conference and Exposition (PEAC), Shenzhen, China, November 2018. (Corresponding Author: Qi Guo.)

C. Tu, Q. Guo, F. Xiao, and J. Gao are with the College of Electrical and Information Engineering, Hunan University, Changsha 410082, China (e-mail: chunming_tu@263.net; qguo_215@163.com; woliaokk123@126; 13162798057@163.com).

F. Jiang is with the School of Electrical and Information Engineering, Changsha University of Science \&Technology, Changsha 410004, China (e-mail: jiamg85521@126.com).

C. Chen is with Electric Power Engineering Group of Lulea Technology University, Skelleftea 93187, Sweden (e-mail: chechen@kth.se).

$\mathrm{X}$. Li is with Nanping Power Supply Company of State Grid, Nanping 353000, China ( e-mail: jygdj@163.com).

Digital Object Identifier 10.24295/CPSSTPEA.2019.00021

\begin{tabular}{|c|c|}
\hline$U_{\text {DVRi }}$ & $\begin{array}{l}\text { The compensated voltage of the initial } \\
\text { operating point in compensation stage. }\end{array}$ \\
\hline$U_{\text {DVRf }}$ & $\begin{array}{l}\text { The compensated voltage of the final operating } \\
\text { point in compensation stage. }\end{array}$ \\
\hline$U_{\text {ri }}$ & $\begin{array}{l}\text { The compensated voltage of the initial operating } \\
\text { point in recovery stage. }\end{array}$ \\
\hline$U_{\text {inj }}$ & Injected voltage in recovery stage. \\
\hline$U_{\text {DVRmax }}$ & Maximum value of injected voltage. \\
\hline$U_{\mathrm{dc}}$ & DC link voltage. \\
\hline$U_{\mathrm{SC}}$ & DC link voltage of super-capacitor. \\
\hline$I_{\mathrm{L}}$ & load current. \\
\hline$I_{\mathrm{L}}^{\prime}$ & load current after the sag. \\
\hline$\theta_{\mathrm{L}}$ & Load power factor angle. \\
\hline$\sigma$ & Phase jump accompanied with the sag issue. \\
\hline$\alpha_{\mathrm{r}}$ & $\begin{array}{l}\text { Phase jump due to the injected voltage of } \\
\text { DVR. }\end{array}$ \\
\hline$\theta_{\text {DVR }}$ & Angle of injected voltage. \\
\hline$\theta_{\text {trans } 1} / \theta_{\text {trans } 2}$ & Angle of injected voltage during transition \\
\hline$/ \theta_{\text {trans } 3}$ & 1,2 or 3 \\
\hline$\theta_{\mathrm{dvr}}$ & $\begin{array}{l}\text { Angle of injected voltage during energy } \\
\text { self-recovery stage. }\end{array}$ \\
\hline$\theta_{\text {DVRi }}$ & $\begin{array}{l}\text { Angle of injected voltage at initial point of } \\
\text { transition } 1 \text {. }\end{array}$ \\
\hline$\theta_{\text {DVRf }}$ & $\begin{array}{l}\text { Angle of injected voltage at final point of } \\
\text { transition } 1 \text {. }\end{array}$ \\
\hline$\theta_{\text {ri }}$ & $\begin{array}{l}\text { Angle of injected voltage at initial point of } \\
\text { recovery stage. }\end{array}$ \\
\hline$\gamma$ & $\begin{array}{l}\text { The phase angle difference between } U_{\text {inj }} \text { and } \\
U_{\mathrm{S}} \text {. }\end{array}$ \\
\hline$\omega$ & Angular frequency. \\
\hline$m_{\max }$ & Maximum modulation ratio. \\
\hline
\end{tabular}

\section{INTRODUCTION}

DOWER electronics is emerging as an advanced technology to modernize electric power systems and enhance their sustainability, flexibility, and high efficiency [1]. The increasing applications of distributed generation, switch-mode power converters, drives, and rapidly changing loads all have contributed to influence system power quality [1]-[4]. One effective technology to solve the voltage quality issues is the employment of the custom-made series active compensator. 


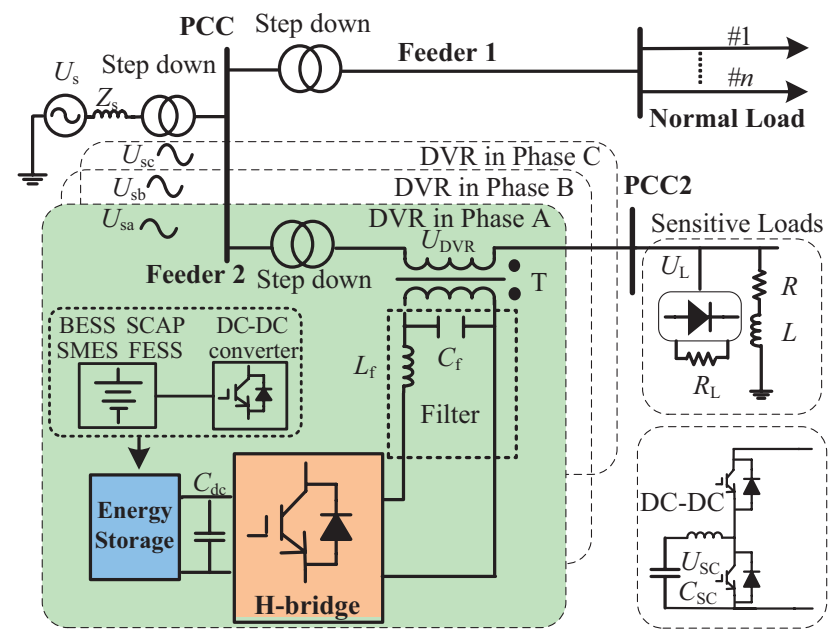

Fig. 1. Typical topology of DVR-based system.

One of the most representative application of this technology is the dynamic voltage restorer (DVR) [5]-[11]. In recent years, different aspects of the DVR have been studied [12]-[19]. The typical topology of DVR is as shown in Fig. 1 [12]-[13], which is mainly composed of an energy storage system or an alternative power source, a voltage source converter, an output filter and a coupling transformer.

The voltage sag issue is commonly associated with a phase jump characteristic in the load side voltage waveform [19]. Further, the value of phase angle jump may be increased by energy-optimized compensation strategies [14]. The phase jump issues worth deep studies because it causes the voltage flicker and may lead to extreme transient currents in the electrical power units such as capacitors, transformers, and motors [20]. These issue were noticed and combined with the DVR's control to make corresponding improvements in [21]. However, the energy in the DC link capacitor continues to be consumed in voltage compensation stage, then, the enhancement of compensation time is limited. An enhanced scheme is proposed in [22]. It mitigates the phase jump in the early stage of compensation and enhances the sag compensation time at the same time. However, this method doesn't cover the optimized exit operation of DVR after voltage sag disappearance, which may cause the occurrence of further phase jump and has seldom been studied. Overall, the large phase jump may occur two times during the whole compensation stage. Besides, for a long sag event with a deeper sag depth, the energy stored in the DC link side is reduce due to a certain nonzero active power injected by the DVR, and consequently the DC-link voltage decreases (gradually). Therefore, another notable issue with the voltage sag is the self-recovery of the DVR's energy storage unit. A self-charging method through the small voltage drop across the DVR terminals to replenish the energy of the DC side is attractive in comparison with the methods using separate charging circuit [23]. However, the former one is implemented at the expense of load voltage amplitude reduction. In [24], by changing the voltage injection phase, the DC link voltage can be managed to be relatively constant during the voltage compensation stage, but this strategy normally doesn't function when the voltage sag disappears. It only has satisfying performance during voltage sag period. Further, to make the DC link voltage recovery to the normal value promptly, a maximum active power absorption strategy is proposed in [25], but the phase jumps in the both early and later stage of the recovery process still deserve further attention.

Overall, the comprehensive optimal scheme of DVR system should include the operation optimization during compensation stage, the rapid recovery of the DC link voltage, and the flexible switching between two stages. An adaptive scheme proposed in this paper features the following superioritise and operational characteristics:

1) The initial operating point of recovery process should be adjusted according to the final state of voltage compensation to avoid any further phase angle jump after fault removal. The perfect linkage between recovery operation and voltage compensation is designed.

2) The DC link voltage after the voltage sag disappearance is recovery to the set value promptly, which ensure the equipment ready for the next compensation. Meanwhile, the injected voltage will not perturb the magnitude and phase angle of load voltage during the whole recovery operation stage.

The paper is organized as follows. Section II describes the operation principle of both traditional schemes and proposed strategy. The analytical study for the updated procedure designed to avoid overmodulation operation is explained in Section II as well. The control scheme is discussed in Section III. Section IV and Section $\mathrm{V}$ shows the simulation and experimental results respectively. Finally, the conclusions are summarized in Section VI.

\section{Voltage Compensation Operation Principle}

\section{A. Traditional Operation Method}

Different strategies can be used by DVR to deliver the voltage compensation. The most popular strategies are the inphase compensation, pre-sag compensation, the reactive power compensation and minimal active power compensation [6]. The latter two energy-optimized compensation strategies can improve the overall effectiveness of the DVR as shown in Fig. 2.

Case 1: If the depth of voltage sag issues is within certain power-factor-dependent limits as depicted in earlier works [15], non-active power is demanded in the compensation stage. The voltage sag depth percentage $k_{\text {sag }}$ must satisfy the relation:

$$
k_{\mathrm{sag}} \leqslant 1-\cos \left(\theta_{\mathrm{L}}\right)
$$

Also, this relation must be satisfied:

$$
k_{\text {sag }}=\left(U_{\text {Lref }}-U_{\mathrm{S}}^{\prime}\right) / U_{\text {Lref }},
$$

where $\theta_{\mathrm{L}}$ is the load power factor angle, $U_{\text {Lref }}$ represents the reference value of load voltage, $U_{\mathrm{S}}$ and $U_{\mathrm{S}}^{\prime}$ are the rated 


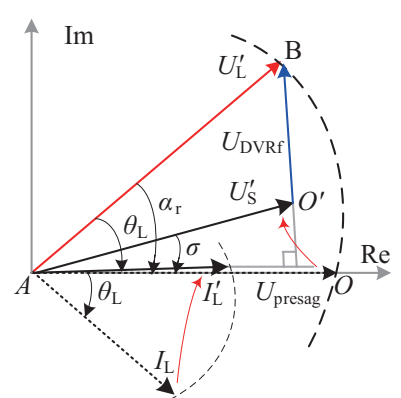

(a)

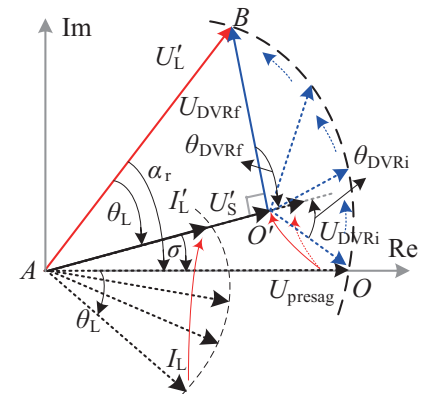

(b)

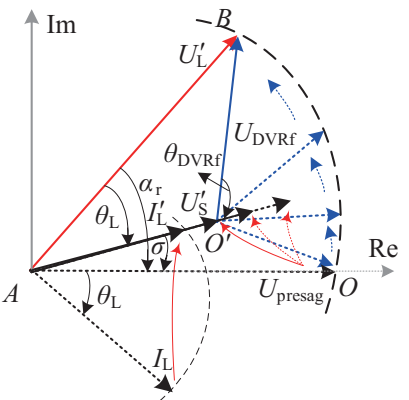

(c)

Fig. 2. Phasor diagram in the voltage compensation stage. (a) Reactive power compensation. (b) Enhanced scheme with a smooth transition while $k_{\text {sag }}<$ $1-\cos \left(\theta_{\mathrm{L}}\right)$. (c) Enhanced scheme with a smooth transition while $k_{\mathrm{sag}}>1-\cos \left(\theta_{\mathrm{L}}\right)$.

voltage and sagged voltage of grid side respectively. The $U_{\text {DVRf }}$ is perpendicular to $I_{\mathrm{L}}^{\prime}$ as seen in Fig. 2(a), $\alpha_{\mathrm{r}}$ is the phase jump induced due to energy-optimized compensation, $\sigma$ is the phase jump accompanies with the voltage sag issues [21], the phase angle of all variables is referenced by the $U_{\mathrm{S}}$. Then, the root-mean-square (RMS) value and the angle of $U_{\text {DVRf }}$ as given in the following:

$$
\begin{gathered}
U_{\mathrm{DVRf}}=U_{\mathrm{L}}^{\prime} \sin \theta_{\mathrm{L}}-\sqrt{\left(U_{\mathrm{S}}^{\prime}\right)^{2}-\left(U_{\mathrm{L}}^{\prime} \cos \theta_{\mathrm{L}}\right)^{2}} \\
\theta_{\mathrm{DVRf}}=\pi-\arccos \left[\frac{\left(U_{\mathrm{S}}^{\prime}\right)^{2}+\left(U_{\mathrm{DVRf}}\right)^{2}-\left(U_{\mathrm{L}}^{\prime}\right)^{2}}{2 U_{\mathrm{S}}^{\prime} U_{\mathrm{DVRf}}}\right]
\end{gathered}
$$

where the phasors of $U_{\mathrm{L}}$ and $U_{\mathrm{L}}^{\prime}$ are the load voltage before and after the sag [20]. Though the DVR protects the sensitive loads against the grid voltage sags based on the energy-optimized strategies, the phase jump of load voltage is existed as can be seen in Fig. 2(a).

For correcting the phase jump on load voltage, an enhanced scheme is proposed in [21], which through a smooth transition represented by the trajectory of the blue curve as shown in Fig. 2(b). Using the relation between $U_{\text {presag }}, U_{\text {DVRi }}$ and $U_{S}^{\prime}$, the RMS value and the angle of $U_{\text {DVRi }}$ given in the following:

$$
\begin{gathered}
U_{\text {DVRi }}=\sqrt{\left(U_{\text {presag }}\right)^{2}+\left(U_{\mathrm{S}}^{\prime}\right)^{2}-2 U_{\text {presag }} U_{\mathrm{S}}^{\prime} \cos (\sigma)} \\
\theta_{\text {DVRi }}=-\left\{\pi-\arccos \left[\frac{\left(U_{\text {DVRi }}\right)^{2}+\left(U_{\mathrm{S}}^{\prime}\right)^{2}-\left(U_{\text {presag }}\right)^{2}}{2 U_{\mathrm{S}}^{\prime} U_{\text {DVRi }}}\right]\right\}
\end{gathered}
$$

To ensure a smooth transition from initial operating points to the final one [15], a transition ramp is defined:

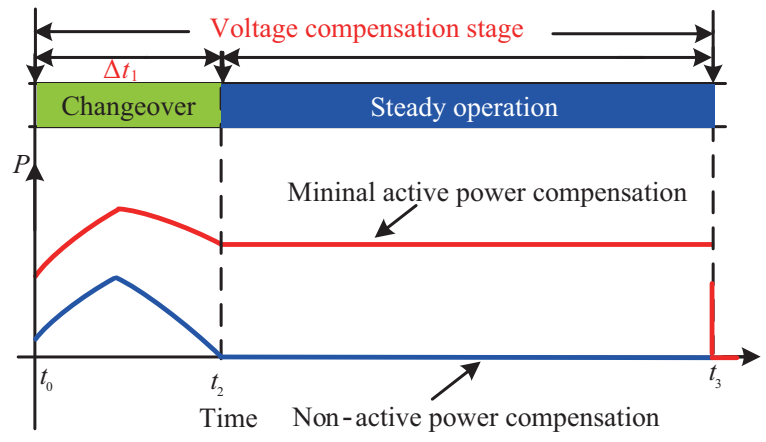

Fig. 3. Active power of DVR system in voltage compensation stage. (a) $k_{\mathrm{sag}}>$ $1-\cos \left(\theta_{\mathrm{L}}\right)$. (b) $k_{\mathrm{sag}} \leqslant 1-\cos \left(\theta_{\mathrm{L}}\right)$.

$$
\theta_{\text {trans } 1}=\theta_{\text {DVRi }}+\frac{\theta_{\text {DVRf }}-\theta_{\text {DVRi }}}{\Delta t_{1}}(t),
$$

where $\theta_{\text {DVRi }}$ is the phase angle of initial operating point, $\theta_{\text {DVRf }}$ is the phase angle of final operating point and can be get as $\pi / 2$, the slope of the transition curve is determined by $\Delta t_{1}$. The diagram of active power afforded by the DVR is provided in Fig. 3 with a blue line. Note that, the DVR only consumes the certain nonzero active power from DC link side during the transition stage.

Case 2: When the voltage sags to $U_{\mathrm{S}}^{\prime}$ with $k_{\mathrm{sag}}>1-\cos \left(\theta_{\mathrm{L}}\right)$, corrects teh sag issues with non-active power is not possible. To achieve the voltage compensation with minimum active power injection, $U_{\mathrm{S}}{ }^{\prime}$ must be made to lie along the direction of $I_{\mathrm{L}}^{\prime}$, and $U_{\mathrm{DVRr}}$ is no longer perpendicular to $I_{\mathrm{L}}^{\prime}$ as shown in Fig. 2(c). Using the relation between $U_{\text {presag }}, U_{\text {DVRf }}$, and $U_{S}^{\prime}$, the RMS value of $U_{\text {DVRf }}$ can be found as

$$
U_{\text {DVRf }}=\sqrt{\left(U_{\mathrm{S}}^{\prime}\right)^{2}+\left(U_{\mathrm{L}}^{\prime}\right)^{2}-2\left(U_{\mathrm{S}}^{\prime}\right)\left(U_{\mathrm{L}}^{\prime}\right) \cos \left(\theta_{\mathrm{L}}\right)} .
$$

Accordingly, substituting (8) into (4), the angle of $U_{\text {DVRf }}$ can be calculated. Then, a smooth transition is similar to case 1. The active power supplied by DVR in this case can be expressed as

$$
P_{\mathrm{DVR}}=P_{\mathrm{L}}-P_{\mathrm{S}}=\sqrt{3} U_{\mathrm{L}} I_{\mathrm{L}} \cos \left(\theta_{\mathrm{L}}\right)-\left(1-k_{\mathrm{sag}}\right) \sqrt{3} U_{\mathrm{L}} I_{\mathrm{L}} .
$$

Note that in this case, the DVR consumes the certain nonzero active power from energy storage during the transition and the steady operating stage, especially the latter, which causes a reduction in the DC link voltage. The diagram of active power afforded by the DVR is provided in Fig. 3 with a red line.

\section{B. Modified Recovery Operation Principle}

1) Modified Recovery Operation Principle. Considering the few attention to the phase jump on the load side after voltage fluctuation removal and the drawback of existing energy recovery strategy, the comprehensive strategy of DVR should ensure the load side voltage quality with the phase jump 

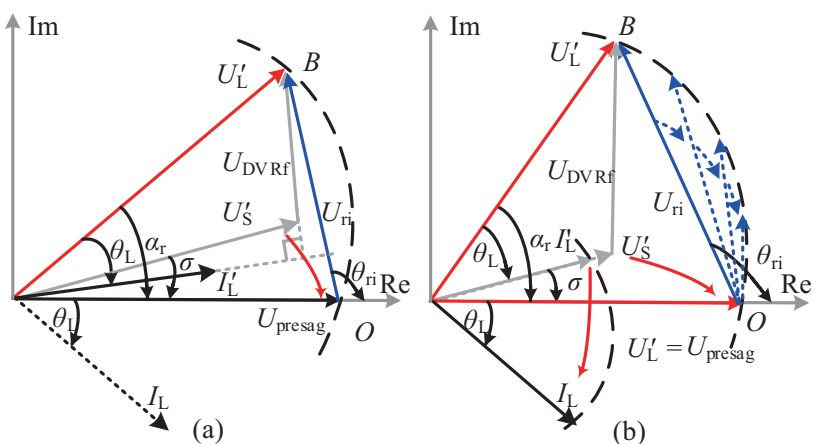

Fig. 4. Phasor diagram for DVR flexible recovery. (a) Operation principle while $k_{\text {sag }}<1-\cos \left(\theta_{\mathrm{L}}\right)$. (b) Operation principle with a smooth transition while $k_{\text {sag }}>1-\cos \left(\theta_{\mathrm{L}}\right)$.

mitigation whether in the initial or later stage of compensation, but also recovers the DC link voltage promptly as soon as possible.

After the disturbances, the system voltage recovers to the normal state where $U_{\mathrm{S}}^{\prime}=U_{\text {presag }}$ and $\sigma=0$. Controlling the smooth withdrawal of DVR from the power grid is the most critical thing in the recovery stage, therefore, another smooth transition is needed. Based on the transition in the voltage compensation stage, the phase jump after fault removal can be avoided by utilizing the instantaneous injected voltage $U_{\text {ri }}$ as can be seen in Fig. 4(a). The injected voltage of initial state in recovery stage satisfies the relation as

$$
\vec{U}_{\text {presag }}+\vec{U}_{\mathrm{ri}}=\vec{U}_{\mathrm{L}}^{\prime}
$$

As seen in Fig. 4 , the $\alpha_{\mathrm{r}}$ is given below

$$
\alpha_{\mathrm{r}}= \begin{cases}\theta_{\mathrm{L}}+\sigma & \text { if } k_{\text {sag }}>1-\cos \left(\theta_{\mathrm{L}}\right) \\ \theta_{\mathrm{L}}+\theta_{\text {DVRf }}-\frac{\pi}{2}+\sigma & \text { if } k_{\text {sag }} \leqslant 1-\cos \left(\theta_{\mathrm{L}}\right) .\end{cases}
$$

Accordingly, using (11), the phase angle and RMS value of the injected voltage can be deduced as

$$
\begin{gathered}
\theta_{\mathrm{ri}}=\pi-\frac{\pi-\alpha_{\mathrm{r}}}{2} . \\
U_{\mathrm{ri}}=\sqrt{\left(U_{\mathrm{L}}^{\prime}\right)^{2}+\left(U_{\text {presag }}\right)^{2}-2\left(U_{\mathrm{L}}^{\prime}\right)\left(U_{\text {presag }}\right) \cos \left(\alpha_{\mathrm{r}}\right)} .
\end{gathered}
$$

The transition mode 2 is defined from initial operating point to the final one, as given in the following:

$$
\theta_{\text {trans } 2}=\theta_{\mathrm{rf}}+\frac{\theta_{\mathrm{rf}}-\theta_{\mathrm{ri}}}{\Delta t_{2}}(t)
$$

where $\theta_{\mathrm{rf}}$ is the phase angle of final operating point and can be get as $\pi / 2, \Delta t_{2}$ determines the slope of the transition curve and is chosen as $30 \mathrm{~ms}$. After smooth changeover, $U_{\mathrm{L}}$ meets the final location as $U_{\text {presag }}$ on diagram as shown in Fig. 4(b).

The aforementioned operation of DVR during the transition 1 and transition 2 can be viewed as an equivalent variable impedance indicated by the black line, and the final operating

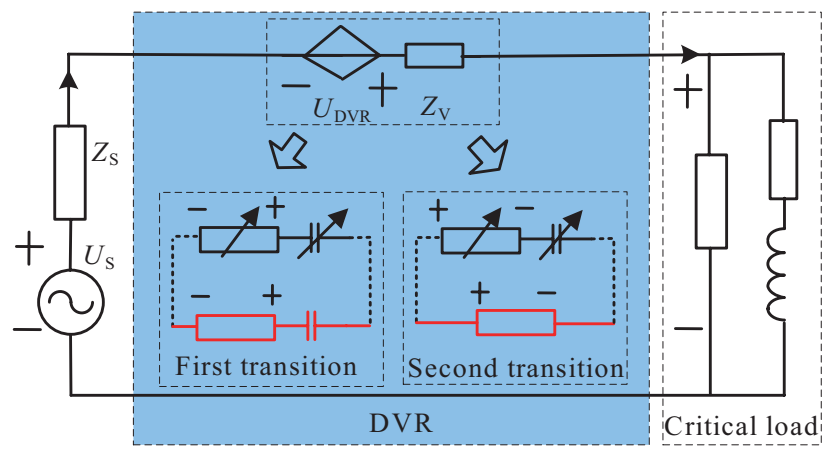

Fig. 5. Equivalent circuit diagram of DVR in voltage compensation stage.

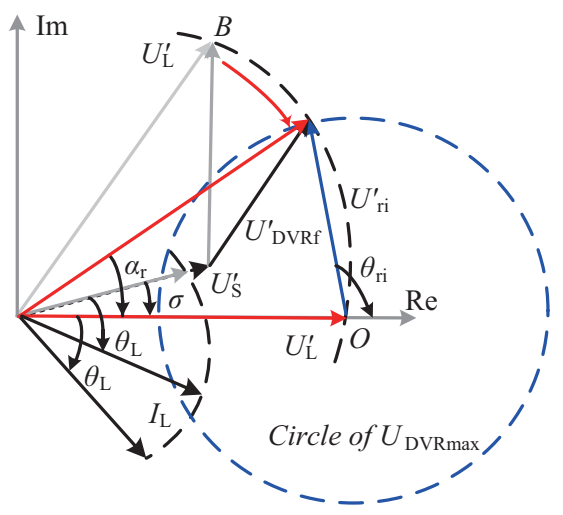

Fig. 6. Updated procedure in voltage compensation stage.

point after transition is indicated by the red line, as shown in Fig. 5. The operation of DVR works as a negative resistive capacitive load during $\Delta t_{1}$ (which represents DVR absorb active power from DC link side to grid) [26]; the operation of DVR works as a positive resistive capacitive load during $\Delta t_{2}$ (which represents DVR absorb active power from grid to DC link side), and then completes with a negligible resistive (which represents the system inherent losses of DVR).

Further, the design limit of the DVR is probably being exceeded at the initial operating point in recovery operation stage in reality. So, the updated procedure of a new injected reference voltage is needed for voltage compensation and recovery to prevent the system from going outside its operating limits.

The dotted circle represents the voltage operation limits with radius $U_{\text {DVRmax }}$ at points $\mathrm{O}$ as shown in Fig. 6, considering the compensation limits of DVR need to satisfy the following relation:

$$
\max \left(U_{\mathrm{DVR}}\right)=m_{\max } U_{\mathrm{dc}}=\max \left(U_{\mathrm{ri}}\right) \leqslant U_{\text {DVRmax }} .
$$

Thus, using (11) and (15), the updated value of $\alpha_{\mathrm{r}}^{\prime}$ can be deduced as

$$
\alpha_{\mathrm{r}}^{\prime}=\operatorname{arc}\left(\frac{\left(U_{\mathrm{L}}^{\prime}\right)^{2}+\left(U_{\text {presag }}\right)^{2}-\left(U_{\text {DVR max }}\right)^{2}}{2\left(U_{\mathrm{L}}^{\prime}\right)\left(U_{\text {presag }}\right)}\right)
$$

Then, the updated value of $U_{\text {DVRf }}$ can be deduced based on $\alpha_{\mathrm{r}}^{\prime}$ as 


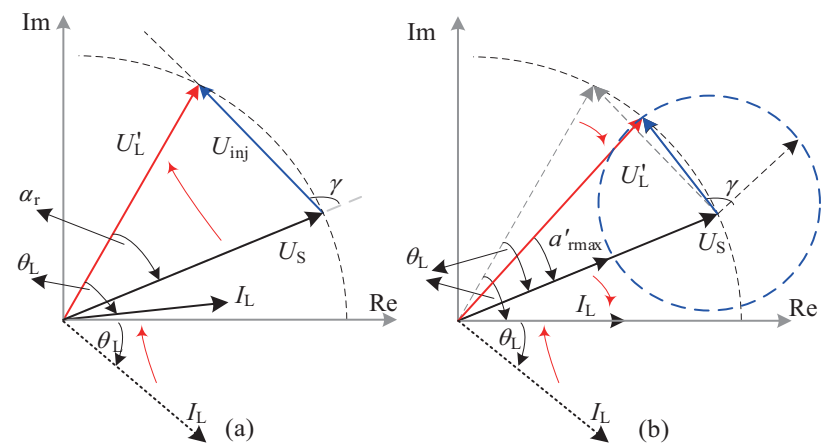

Fig. 7. The phasor diagram of the updated procedure in energy self-recovery stage. (a) Operation principle when over modulation does not occur. (b) Operation principle in case of over modulation.

$$
U_{\text {DVRf }}^{\prime}=\sqrt{\left(U_{\mathrm{S}}^{\prime}\right)^{2}+\left(U_{\mathrm{L}}^{\prime}\right)^{2}-2\left(U_{\mathrm{S}}^{\prime}\right)\left(U_{\mathrm{L}}^{\prime}\right) \cos \left(\alpha_{\mathrm{r}}^{\prime}-\sigma\right)}
$$

Hence, substituting (24) into (4), we can obtain the updated value of $\theta_{\text {DVRf }}$. Finally, after the initial operating point are regulated, the two smooth transition using (6) and (14) can be well completed.

2) Energy Self-Recovery Operation Principle. It must be pointed out that the energy of DC link side needs to be restored while the longer sag issues happens meanwhile the sag depth exceed the limit given in (1). As mentioned above, the operation of DVR works as a positive capacitive load during $\Delta t_{2}$, which can be used for energy recovery of DVR. As can be seen in Fig. 7, the amplitudes of $U_{\mathrm{L}}$ is the same with $U_{\mathrm{S}}$ while the phase angles are different, we have the injected voltage $U_{\text {inj }}$ generated by DVR. In this case, if $\gamma<90^{\circ}$, the active power flows from DVR to the grid side; if $\gamma<90^{\circ}$, the active power flows from grid to the DVR, keep this state unchanged thus the energy self-recovery of DC link can be realized. The supplied active power is given by

$$
P_{\text {in }}=U_{\mathrm{S}} I_{\mathrm{L}} \cos \left(\varphi-\alpha_{\mathrm{r}}\right)-U_{\mathrm{L}} I_{\mathrm{L}} \cos \left(\theta_{\mathrm{L}}\right) .
$$

According to (18), the supplied active power depends on the value of $\alpha_{\mathrm{r}}$, as the other parameters of (18) are constant. The larger value of $\alpha_{\mathrm{r}}$, the greater energy transferred between DVR and the system, which shorten the time-consuming of the recovery process. With the consideration of the $U_{\mathrm{L}}^{\prime}$ and $U_{\text {presag }}$ as 1 p.u., it is obvious to know that we have the maximum power of DVR absorbed while $\alpha_{\text {rmax }}=\theta_{\mathrm{L}}$ as

$$
P_{\text {inmax }}=S_{\mathrm{L}}\left[1-\cos \left(\theta_{\mathrm{L}}\right)\right]
$$

The phase angle and amplitude of $U_{\text {inj }}$ can be obtained as

$$
\begin{aligned}
& \gamma=\pi-\frac{1}{2}\left(\pi-\alpha_{\mathrm{r}}\right)=\frac{1}{2}\left(\pi+\alpha_{\mathrm{r}}\right) . \\
& U_{\mathrm{inj}}=\sqrt{U_{\mathrm{L}}^{2}+U_{\mathrm{S}}^{2}-2 U_{\mathrm{L}}^{\prime} U_{\mathrm{S}} \cos \left(\theta_{\mathrm{L}}\right)} .
\end{aligned}
$$

Similarly, the maximum operating point in energy selfrecovery stage is determined by the designing limit of the

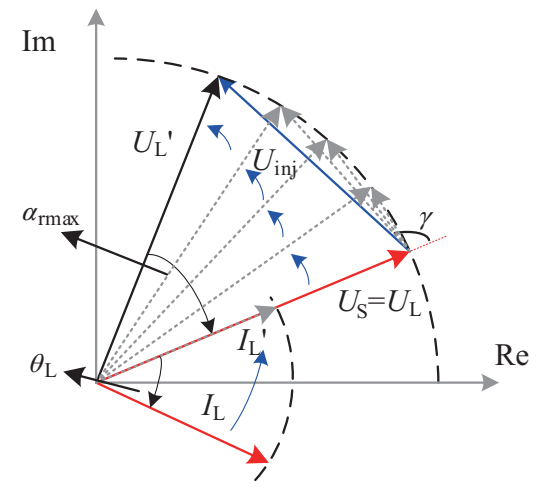

Fig. 8. The phasor diagram of the flexible switching in the initial stage of self-recovery.

DVR. The operating point of DVR needs to regulate once the following limits are exceeded as

$$
m_{\text {max }} U_{\mathrm{dc}}<U_{\mathrm{inj}}=\sqrt{U_{\mathrm{L}}^{2}+U_{\mathrm{S}}^{2}-2 U_{\mathrm{L}}^{\prime} U_{\mathrm{S}} \cos \left(\theta_{\mathrm{L}}\right)} .
$$

From Fig. 7(b), the updated value of $\alpha_{\mathrm{r}}^{\prime}$ can be calculated by (16), then the value of $\gamma$ can be recalculated as well.

3) Modified Energy Self-recovery Operation Principle. In energy recovery stage, the most key issue is manage the DC link voltage to reference value and realize the smooth access of DVR to the maximum power operating point. Thus, if $U_{\mathrm{SC}}$ is less than $U_{\mathrm{SCmin}}$ (the energy storage using super-capacitor on DC link side is considered in this paper, and the voltage of the super-capacitor is determined to be the standard for energy selfrecovery stage starting up or not), a smooth transition mode 3 is needed to achieve the maximum energy absorption of DVR.

The vector diagram of the whole flexible switching process is shown in Fig. 8. The $\theta_{\text {init }}$ and $\theta_{\text {stable }}$ are the initial and steady state phase angle of $U_{\text {inj }}$, respectively, the slope of the transition curve is determined by $\Delta t_{3}$. Then we can get $\theta_{\text {init }}=0$ and $\theta_{\text {stable }}=\gamma$, the transition mode 3 is defined from initial operating points to the final one, as given in the following:

$$
\theta_{\text {dvr }}=\theta_{\text {trans3 }}=\theta_{\text {init }}+\left(\frac{\theta_{\text {stable }}-\theta_{\text {init }}}{\Delta t_{3}}\right) t=\frac{\gamma}{\Delta t_{3}} t .
$$

Once the energy self-recovery stage is completed, the transition mode 2 is initiated as depicts in Fig. 4, and the transition angle is given as follows

$\theta_{\text {dvr }}=\theta_{\text {trans } 2}=\theta_{\text {stable }}+\left(\frac{\theta_{\text {final }}-\theta_{\text {stable }}}{\Delta t_{2}}\right) t=\gamma+\frac{\pi / 2-\gamma}{\Delta t_{2}} t$.

Overall, the operation modes of the DVR for energy selfrecovery mentioned above are as follows.

Mode 1: As for the case of $U_{\mathrm{SC}}>U_{\mathrm{SCmin}}$ after the sag disappear, considering the certain active power generated by DVR is relatively small, the energy self-recovery operation is inactivated and the recovery operation with smooth transition mode 2 is activated, as depicts and shown in Fig. 9 with black line from $t_{1}$ to $t_{2}$.

Mode 2: As for the case of $U_{\mathrm{SC}}<U_{\mathrm{SCmin}}$ after the voltage sag 


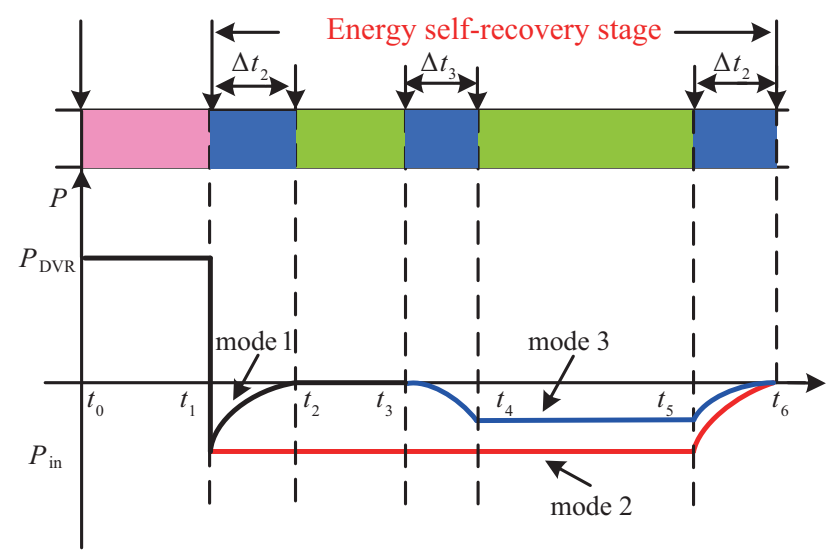

Fig. 9. Active power of DVR system in energy self-recovery stage.

disappear, the energy self-recovery operation is activated and the controller keeps the DVR working at the initial operating point of recovery operation unchanged until $U_{\mathrm{SC}}>U_{\text {SCref, }}$, then the smooth transition mode 2 is activated, as depicts and shown in Fig. 9 with red line from $t_{1}$ to $t_{6}$.

Mode 3: As for the case of normal conditions to restore the DC link voltage, the energy self-recovery operation is initiated by the smooth transition mode 3 and keeping the DVR work as maximum power operating point of recovery stage unchanged until $U_{\mathrm{SC}}>U_{\mathrm{SCref}}$, then the smooth transition mode 2 is activated, as depicts and shown in Fig. 9 with blue line from $t_{3}$ to $t_{6}$.

\section{Overall Control Scheme}

Owing to the randomness of voltage sag, $U_{\mathrm{S}}$ and $U_{\mathrm{L}}$ are measured in real time. Under normal condition, the DVR works in stand-by mode. The voltage compensation stage is initiated while $k_{\mathrm{sag}}>k_{\mathrm{ref}}=0.05$. Then, the operation mode and the operating point are determined based on the values of $k_{\mathrm{sag}}$ and $\cos \left(\theta_{\mathrm{L}}\right)$. Further, once the amplitude of $U_{\mathrm{DVR}}$ bigger than the given value $U_{\text {DVRmax }}$, the injected voltage angle during the voltage compensation stage and energy self-recovery stage is regulated thus avoiding overmodulation.

Fig. 10 depicts the detailed block diagram of the proposed comprehensive scheme. To realize the voltage compensation, the vital step involves obtaining the reference injected voltage angle of DVR. The phase calculation block computes the phase angle $\theta_{\text {DVRf }}$ and $\theta_{\text {DVRi }}$. Then, the DVR injection angle is obtained through the transition 1 and transition 2. Similarly, to realize the energy self-recovery, the vital step involves obtaining the value of $\gamma$. Then, the DVR injection angle is obtained through the transition 3 and transition 2. The DVR reference voltage $U_{\text {DVRref }}$ or $U_{\text {injref }}$ is obtained and compared with the actual voltage in the stationary reference frame. A proportionalintegral (PI) controller is used for accurate tracking of $U_{\text {DVRref }}$ or $U_{\text {injer }}$. After SPWM modulation technology is applied, the driving signal of IGBT is obtained [27]. Further, the energy exchange between super-capacitor and $C_{\mathrm{dc}}$ is done by DC/DC converter, and the detailed control strategy has been described in [28] already.

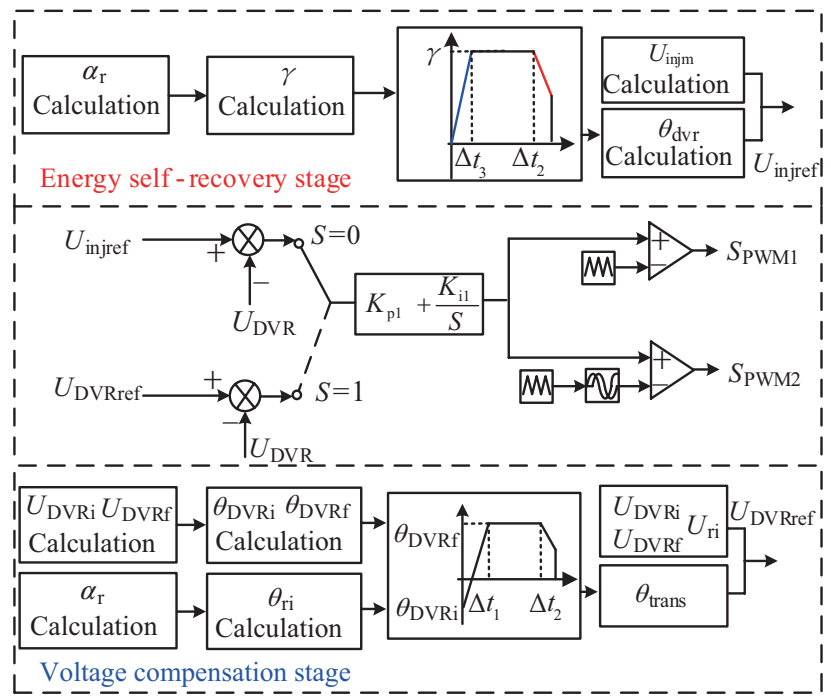

Fig. 10. Control strategy of DVR for voltage compensation and energy selfrecovery.

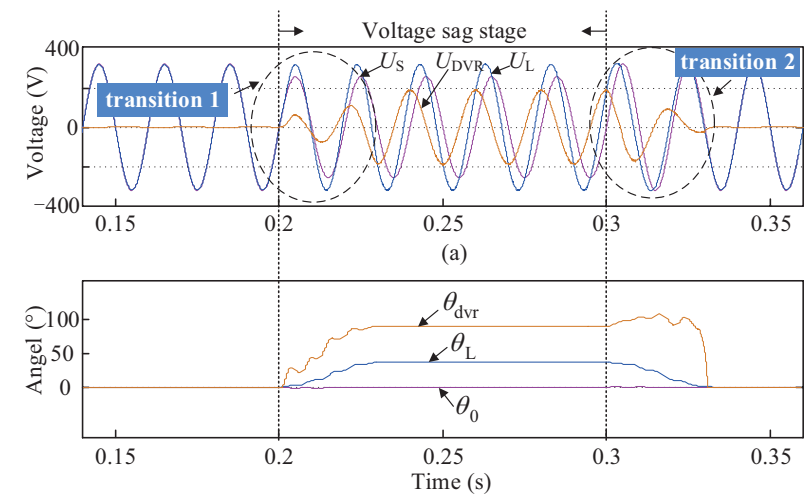

(b)

Fig. 11. Simulation waveforms of when $k_{\text {sag }}$ is 0.8 p.u.

\section{Simulation Results}

\section{A. Simulation Results During Voltage Compensation Stage}

In this section, a MATLAB/SIMULINK model in single phase as shown in Fig. 1 is built, and the performance of proposed control scheme is validated for various sag cases. The system performance is carried out using solver 23 tb in variable step with a sample time of $20 \mu \mathrm{s}$. The simulation parameters are presented in Appendix.

Fig. 11 and Fig. 12 show the simulation waveforms in voltage compensation stage using the proposed strategy. In Fig. 11, the system voltage drops to 0.8 p.u. during $0.2 \sim 0.3 \mathrm{~s}$. The result shows that the DVR with flexible switching control can smoothly enter and exit the state of minimum energy compensation, which ensure negligible phase angle jump to the load voltage. Fig. 12 shows the power exchange between DVR and system. The diagram shows the inductive reactive power is output from DVR while the active power $P_{\mathrm{DVR}}$ is almost remain at zero as shown in Fig. 12(a). In addition, as seen from Fig. 12(b), the system active power $P_{\mathrm{S}}$ remains unchanged 


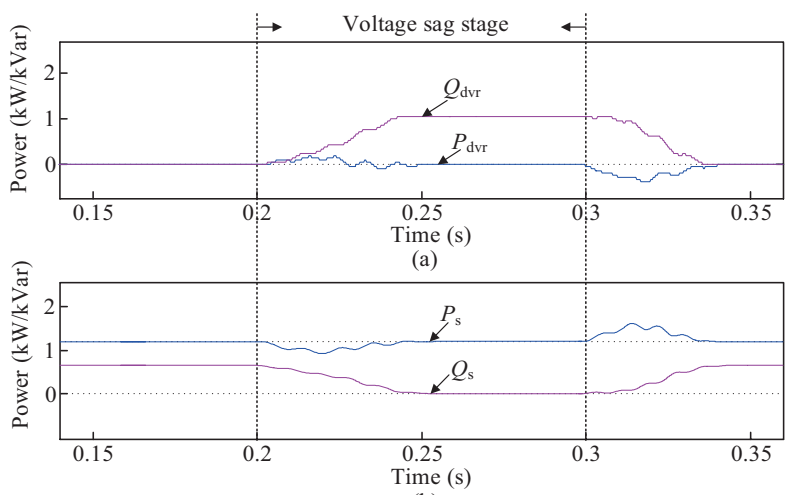

(b)

Fig. 12. Power waveforms of DVR and system when $k_{\text {sag }}$ is 0.8 p.u.
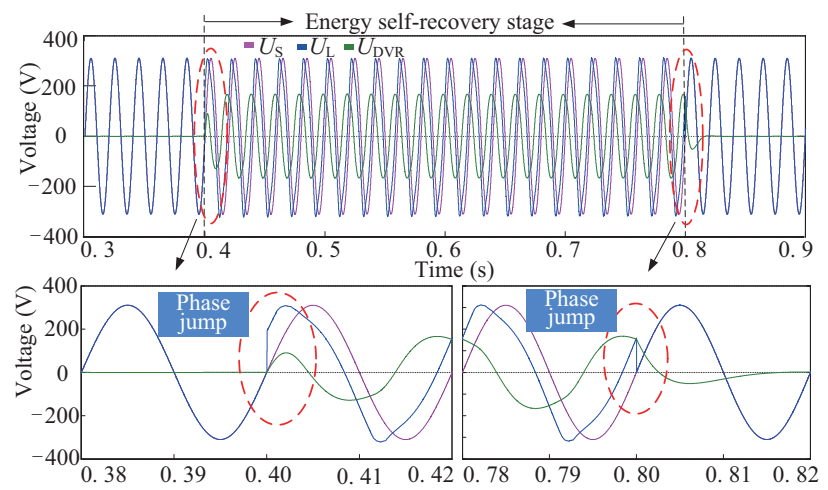

Fig. 13. Simulation waveforms of power grid voltage and load voltage in energy self-recovery stage.

to maintain the demand of the load side, while the reactive power of the system side $Q_{\mathrm{S}}$ almost remain at zero, the DVR compensates all reactive power on the load side.

\section{B. Simulation Results During Energy Self-Recovery Stage}

In this case, the energy self-recovery operation of DVR is executed. The reference value of $U_{\mathrm{dc}}$ and $U_{\text {DVRmax }}$ is set to $300 \mathrm{~V}$ and $250 \mathrm{~V}$ respectively. To verify the effectiveness of the energy self-recovery strategy presented in this paper, the reference value of $U_{\mathrm{SC}}$ is changed from $50 \mathrm{~V}$ to $60 \mathrm{~V}$. The values of $1.414 U_{\mathrm{rf}}$ is calculated as $189 \mathrm{~V}$ using (8). Hence, as can be seen from Fig. 13, the energy self-recovery stage is initiated at $0.40 \mathrm{~s}$. The phase angle $\alpha_{\max }$ increases to $37.1^{\circ}$ directly as shown in Fig. 14, then the DVR absorbs energy from the grid to DC energy storage module. The amplitude of $U_{\mathrm{L}}$ is always consistent with $U_{\mathrm{S}}$ as can be seen in Fig. 13. Seen from Fig. 15, $U_{\text {dc }}$ maintains at $300 \mathrm{~V}$ and the $U_{\text {sc }}$ rises to the value of $60 \mathrm{~V}$ at $0.80 \mathrm{~s}$ (the displayed $U_{\mathrm{dc}}$ has been reduced by four times). While $U_{\text {sc }}$ is restored to $60 \mathrm{~V}$ in $0.80 \mathrm{~s}$, it is determined that the energy self-recovery stage is completed, the phase angle between $U_{\mathrm{s}}$ and $U_{\mathrm{L}}$ decreases to $\alpha_{\mathrm{r}}=0^{\circ}$ directly.

The above simulation results show that the proposed strategy can realize the energy self-recovery of DC link side. As shown in Fig. 13, although the amplitude of the $U_{\mathrm{L}}$ in the energy selfrecovery stage is consistent with the $U_{\mathrm{S}}$, it can be seen that the energy self-recovery brings a large phase angle jump to the

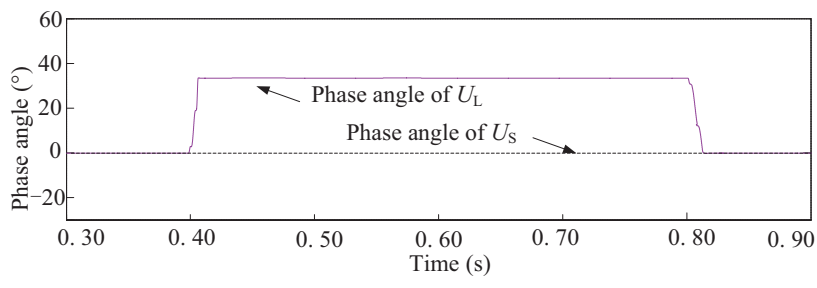

Fig. 14. Phase diagram of grid voltage and load voltage in energy selfrecovery stage.

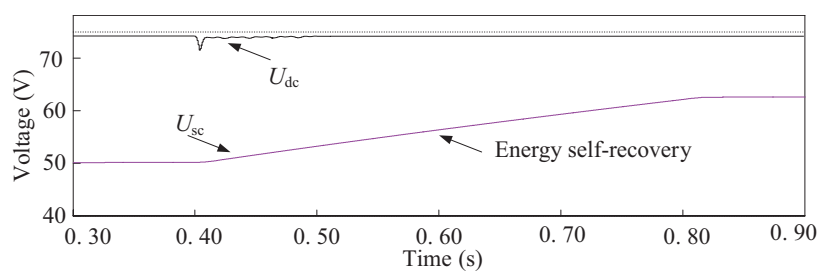

Fig. 15. Simulation waveforms of DC link voltage in the energy self-recovery stage.

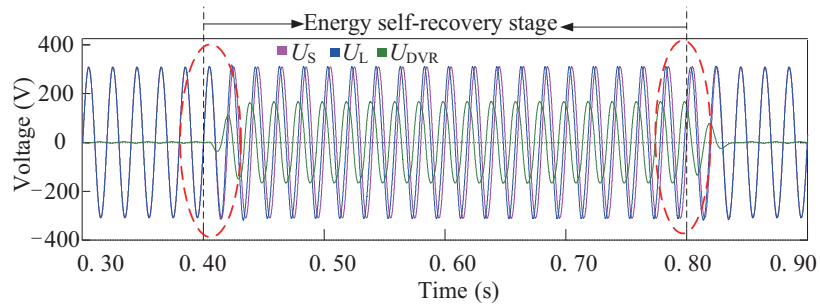

Fig. 16. Simulation waveforms of power grid voltage and load voltage in optimal energy self-recovery stage.

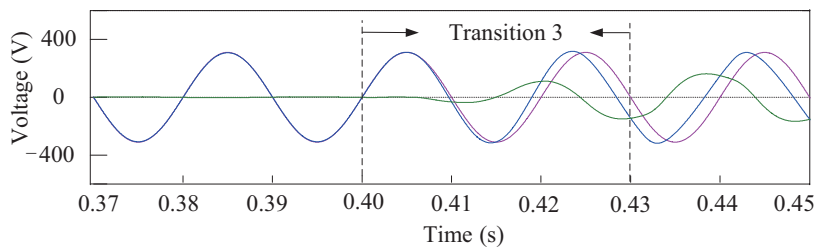

Fig. 17. Initial flexible handover in optimal energy self-recovery stage.

load voltage at the beginning and the end of the compensation.

\section{Simulation Results During Energy Self-Recovery Stage Using Optimized Strategy}

The simulation scenario is same as the condition mentioned above. With the introduction of $\theta_{\text {trans } 3}$ and $\theta_{\text {trans } 2}$, the amplitude of $U_{\mathrm{L}}$ is always consistent with $U_{\mathrm{S}}$ as can be seen in Fig. 16Fig. 20.

From Fig. 19, the controller makes the phase difference between $U_{\mathrm{S}}$ and $U_{\mathrm{L}}$ slowly increases until $\alpha_{\mathrm{rmax}}=\varphi=37.1^{\circ}$ and keep this state unchanged, then the DVR absorbs energy from the grid to DC energy storage module as shown in Fig. 20. While $U_{\text {sc }}$ is restored to $60 \mathrm{~V}$ at $0.80 \mathrm{~s}$, it is determined that the energy self-recovery stage is completed, the phase angle between the two slowly decreases until $\alpha_{\mathrm{r}}=0^{\circ}$. The specific phase angle change process is shown in Figs. 17 and18. Further, Fig. 16 


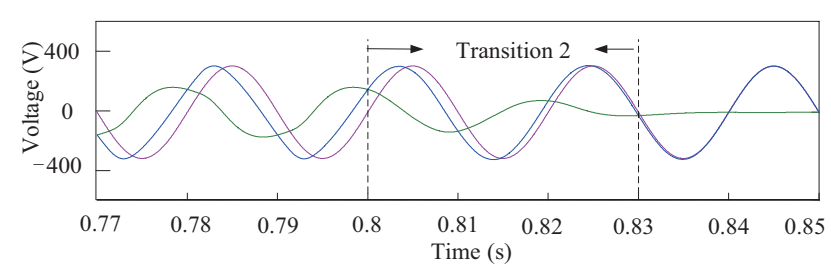

Fig. 18. Final flexible handover in optimal energy self-recovery stage.

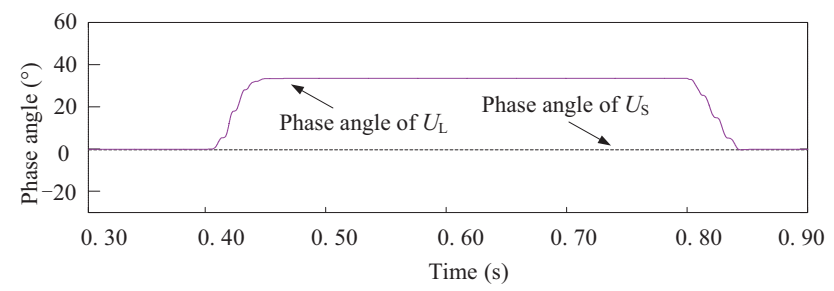

Fig. 19. Phase diagram of grid voltage and load voltage in optimal energy selfrecovery stage.

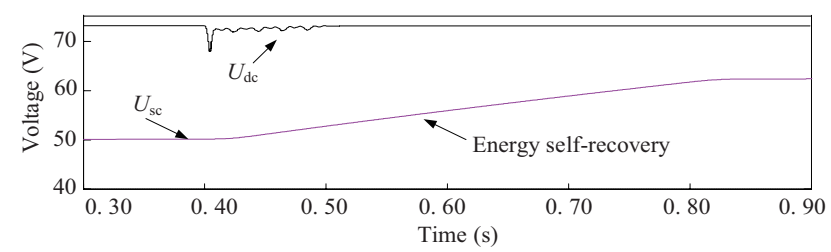

Fig. 20. Simulation waveforms of de ling side voltage under the mode of optimal self-recovery stage.

shows that the effect of energy self-recovery process on the amplitude or phase angle jump of load voltage $U_{\mathrm{L}}$ can be ignored through two smooth transition.

\section{EXPERIMENTAL RESULTS}

The controller hardware-in-the-loop (CHIL) experiments are carried out to demonstrate the effectiveness and feasibility of the proposed strategy. The RT-LAB real-time system is based on Opal-RT [29]-[31], and the single phase model of DVR was carried out in the RT-LAB with a step of $10 \mu$ s. Signals (i.e., the voltage and current) were measured at a sampling frequency of $10 \mathrm{kHz}$, and output to the I/O port of an external TMS320F2812 DSP controller through the interface card.

Case 1: Voltage sag compensation with the phase jump mitigation

In the first scenario, the reference value of $U_{\mathrm{dc}}$ and $U_{\text {DVRmax }}$ are set to $300 \mathrm{~V}$ and $250 \mathrm{~V}$ respectively. The voltage sag issue is initiate at $t_{1}$, the system voltage drops to 0.8 p.u. and last for 10 cycles [meeting the limit given in (1)].

The values of $1.414 U_{\text {DVRf }}$ and $1.414 U_{\text {ri }}$ are calculated as $189 \mathrm{~V}$ and $248 \mathrm{~V}$ using (8) and (13), respectively [meeting the limit given in (15)]. Hence, as seen in Fig. 21(a), the controller makes the DVR gradually shift to the non-active power compensation through transition 1 at $t_{1}$, and then maintains this state unchanged. The phase difference between $U_{\mathrm{DVR}}$ and

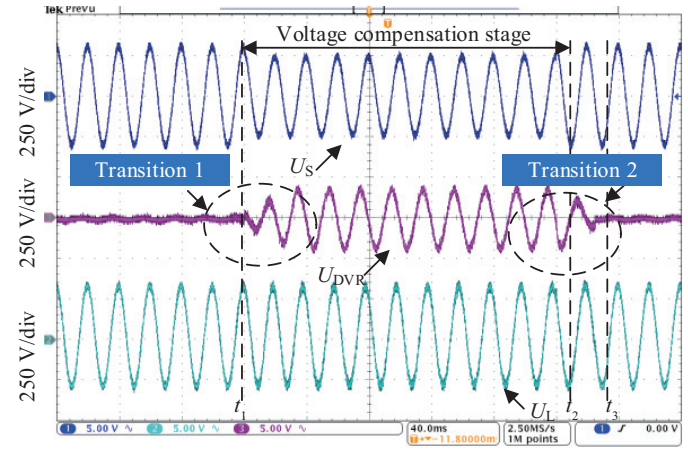

(a) Time $40 \mathrm{~ms} / \mathrm{div}$

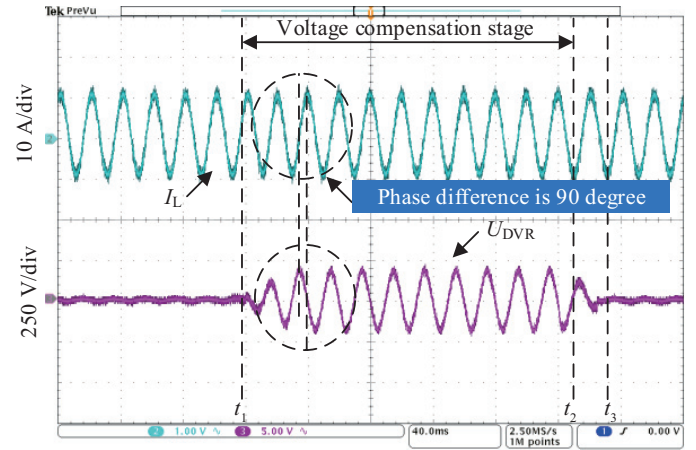

(b) Time $40 \mathrm{~ms} / \mathrm{div}$

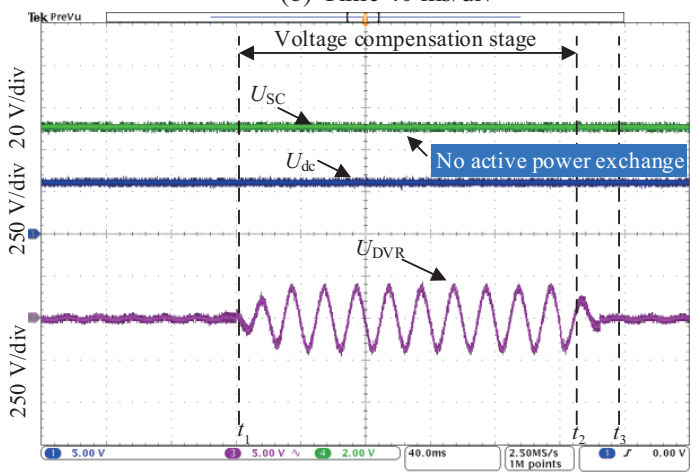

(c) Time $40 \mathrm{~ms} / \mathrm{div}$

Fig. 21. Experimental waveforms when $k_{\text {sag }}$ is 0.8 p.u. (a) $U_{\mathrm{S}}, U_{\mathrm{DVR}}, U_{\mathrm{L}}$. (b) $I_{\mathrm{L}}$, $U_{\text {DVR. }}$ (c) $U_{\mathrm{dc}}, U_{\mathrm{SC}}, U_{\mathrm{DVR}}$.

$I_{\mathrm{L}}$ is $90^{\circ}$ as shown in Fig. 21(b). Fig. 21(c) shows a negligible constant drop in the DC link voltage. The operation modes of the DVR for energy self-recovery can be defined as mode 1 , the recovery stage is initiated at $t_{2}$, and an effective linkage is formed with the final operating point of the compensation stage. The phase difference between $U_{\mathrm{L}}$ and $U_{\mathrm{S}}$ decreases slowly until they finally coincide through the transition 2 . The amplitude of $U_{\mathrm{L}}$ is kept constant, as shown in Fig. 21(a).

Case 2: Energy self-recovery during normal condition

In the second scenario, the reference value of $U_{\mathrm{dc}}$ and $U_{\text {DVRmax }}$ are set to $200 \mathrm{~V}$ and $150 \mathrm{~V}$ respectively. To verify the effectiveness of the energy self-recovery strategy presented in this paper, the reference value of $U_{\mathrm{SC}}$ during energy selfrecovery is set to from $50 \mathrm{~V}$ to $65 \mathrm{~V}$, and the operation mode of the DVR for energy self-recovery can be defined as mode 2 . 


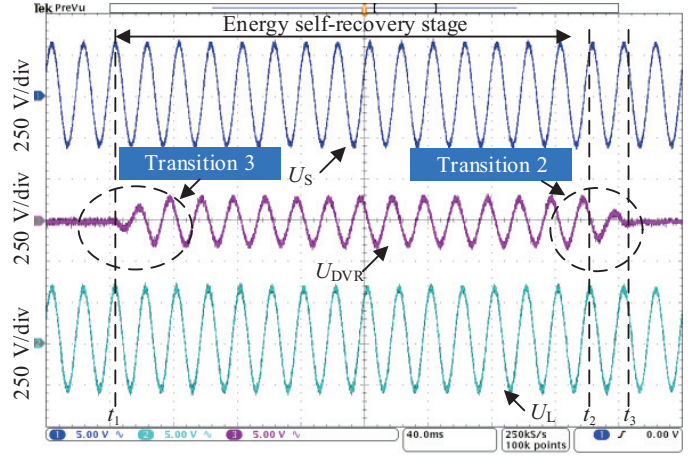

(a) Time $40 \mathrm{~ms} / \mathrm{div}$

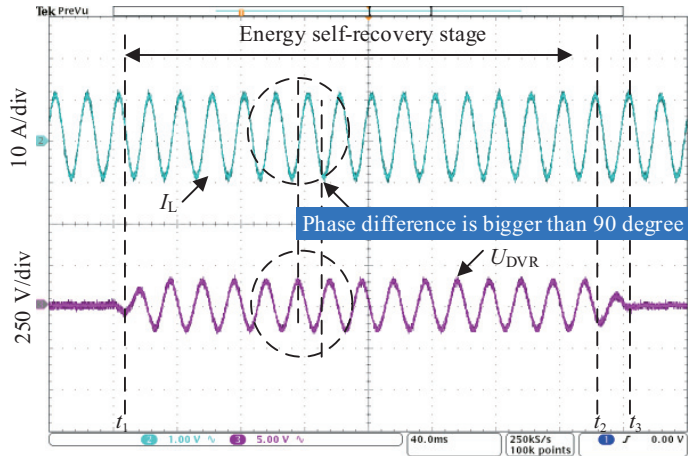

(b) Time $40 \mathrm{~ms} / \mathrm{div}$

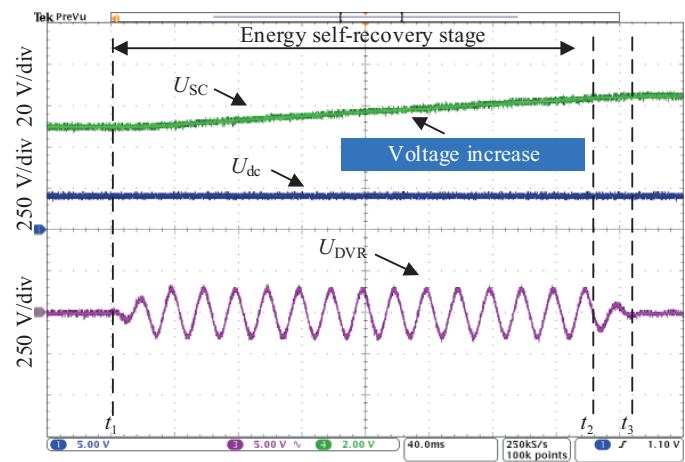

(c) Time $40 \mathrm{~ms} / \mathrm{div}$

Fig. 22. Experimental waveforms in energy self-recovery stage. (a) $U_{\mathrm{S}}, U_{\mathrm{DVR}}$, $U_{\mathrm{L}}$. (b) $I_{\mathrm{L}}, U_{\mathrm{DVR}}$. (c) $U_{\mathrm{dc}}, U_{\mathrm{SC}}, U_{\mathrm{DVR}}$.

The values of $1.414 U_{\text {injm }}$ can be calculated as $248 \mathrm{~V}$ using (13) [exceeding the limit given in (15)], thus, the final operating point during the voltage compensation stage is regulated to $1.414 U_{\mathrm{ri}}=150 \mathrm{~V}$, and $\alpha_{\mathrm{r}}^{\prime}$ can be calculated as $27.91^{\circ}$ using (16). As seen in Fig. 22(b), the phase difference between $U_{\mathrm{L}}$ and $U_{\mathrm{S}}$ increases slowly through transition 3 from $t_{1}$, and maintains this state unchanged until phase difference increase to $27.91^{\circ}$.

Once the energy self-recovery stage is finished, the transition 2 is initiated to make the phase difference between $U_{\mathrm{L}}$ and $U_{\mathrm{S}}$ decreases slowly until they finally coincide. The amplitude of $U_{\mathrm{L}}$ is kept constant, as shown in Fig. 22(a).

Case 3: Energy self-recovery after voltage compensation stage is completed

In the third scenario, the load power factor is changed from 0.80 to $0.85,20 \%$ voltage sag that last for 30 cycles [meeting

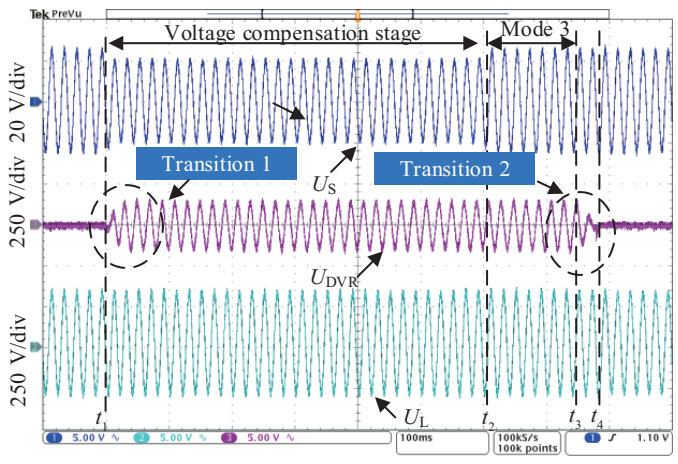

(a) Time $40 \mathrm{~ms} / \mathrm{div}$

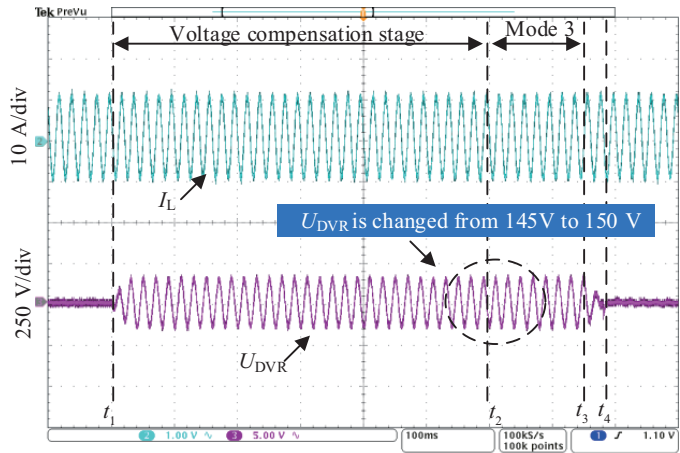

(b) Time $40 \mathrm{~ms} / \mathrm{div}$

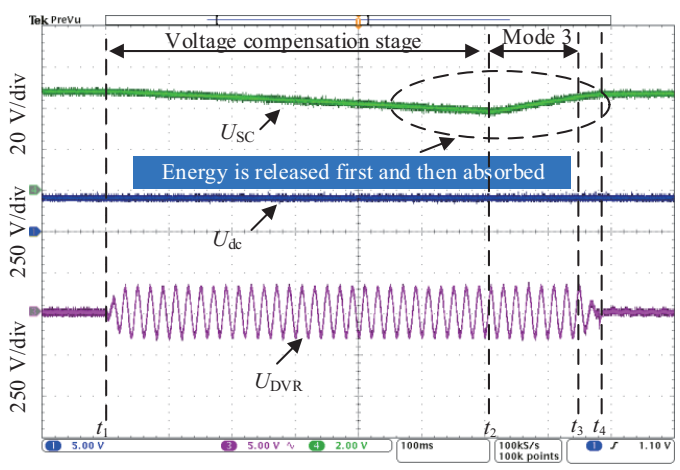

(c) Time $40 \mathrm{~ms} / \mathrm{div}$

Fig. 23. Experimental waveforms when $k_{\text {sag }}$ is 0.8 p.u. with energy selfrecovery stage activation. (a) $U_{\mathrm{S}}, U_{\mathrm{DVR}}, U_{\mathrm{L}}$. (b) $I_{\mathrm{L}}, U_{\mathrm{DVR}}$. (c) $U_{\mathrm{dc}}, U_{\mathrm{SC}}, U_{\mathrm{DVR}}$.

the limit given in (1)] and is initiated at $t_{1}$ as well. The reference value of $U_{\mathrm{dc}}$ and $U_{\text {DVRmax }}$ is set to $200 \mathrm{~V}$ and $150 \mathrm{~V}$ respectively. The values of $1.414 U_{\text {DVRf }}$ and $1.414 U_{\text {ri }}$ are calculated as $189 \mathrm{~V}$ and $248 \mathrm{~V}$ using (8) and (13), respectively [exceeding the limit given in (15)]. Thus, the final operating point during the voltage compensation stage is regulated at $1.414 U_{\mathrm{ri}}=150 \mathrm{~V}$, and $\alpha_{\mathrm{r}}^{\prime}$ can be calculated as $27.91^{\circ}$ using (16). Then, as seen in Fig. 23(b), the controller makes the DVR gradually shift to the minimal active power compensation through transition 1 from $t_{1}$, and maintains this state unchanged until voltage sag disappears at $t_{2}$. The phase difference between $U_{\mathrm{DVR}}$ and $I_{\mathrm{L}}$ is not equal to $90^{\circ}$ as shown in Fig. 23(b).

Fig. 23(c) shows a drop in $U_{\mathrm{SC}}$. It means the active power has been absorbed from DVR to grid. Therefore, the transition 2 is not initiated once the sag disappears. In this case, the operation mode of the DVR for energy self-recovery is defined 
as mode 3, which makes the DVR absorbs the active power to DC link side thus $U_{\mathrm{SC}}$ is increase to the reference value $50 \mathrm{~V}$ at $t_{3}$, as shown in Fig. 23(c). Once the energy self-recovery stage is finished, the transition 2 is initiated to make the phase difference between $U_{\mathrm{L}}$ and $U_{\mathrm{S}}$ decreases slowly until they finally coincide. The amplitude of $U_{\mathrm{L}}$ is kept constant, as shown in Fig. 23(a).

\section{CONCLUSION}

In this paper, an adaptive scheme for DVR to voltage sag compensation and energy self-recovery has been presented. The adaptive schemes improve the voltage quality of sensitive loads by protecting them during grid voltage sags with phase angle jump. The optimized energy self-recovery strategy recovers the DC link voltage and mitigate the phase jump in energy self-recovery stage as well. Further, the updated procedure for injected reference voltage ensures the DVR system is adapted to different working cases. The simulation and the experimental results of DVR under different cases verify the effectiveness of the proposed strategy.

\section{APPENDIX}

Source parameters: $U_{\mathrm{S}}=310 \mathrm{~V}, Z_{\mathrm{S}}=0.05 \Omega, f_{0}=50 \mathrm{~Hz}$.

Load parameters: $Z_{\text {load }}=25 \Omega$, Load $P F=0.8$.

DC link capacitor: $C_{\mathrm{dc}}=6 \mathrm{mF}$.

Super-capacitor: $C_{\mathrm{SC}}=100 \mathrm{mF}$.

Reference Voltage of SC: $U_{\mathrm{SC}}=50 \mathrm{~V}$.

LC filter inductor: $L_{\mathrm{f}}=2 \mathrm{mH}$.

LC filter capacitor: $C_{\mathrm{f}}=15 \mu \mathrm{F}$.

Transition duration $\left(\Delta t_{1}, \Delta t_{2}, \Delta t_{3}\right): 30 \mathrm{~ms}$.

Series transformer parameters:

Turn ratio: 1:1;

Primary voltage: $380 \mathrm{~V}$;

Secondary voltage: $380 \mathrm{~V}$;

Power rating : $50 \mathrm{kVA}$;

Series transformer $U_{\mathrm{k}}: 4 \%$;

Magnetization resistance: 300 p.u.;

Magnetization inductance: 300 p.u.

\section{REFERENCES}

[1] Z. Shuai, D. Liu, J. Shen, C. Tu, Y. Cheng, and A. Luo, "Series and parallel resonance problem of wideband frequency harmonic and its elimination strategy," IEEE Transactions on Power Electronics, vol. 29, no. 4, pp. 1941-1951, Apr. 2014.

[2] J. G. Nielsen and F. Blaabjerg, "A detailed comparison of system topologies for dynamic voltage restorers," IEEE Transactions on Industrial Electronics, vol. 41, no. 5, pp. 1272-1280, Sep. 2005.

[3] A. Javadi, A. Hamadi, L. Woodward, and K. Al- Haddad, "Experimental investigation on a hybrid series active power compensator to improve power quality of typical households," IEEE Transactions on Industrial Electronics, vol. 63, no. 8, pp. 4849-4854, Aug. 2016.

[4] A. Javadi and K. Al-Haddad, "A single-phase active device for power quality improvement of electrified transportation," IEEE Transactions on Industrial Electronics, vol. 62, no. 5, pp. 3033-3041, May 2015.

[5] C. Tu, Q. Guo, Y. Sun, F. Xiao, and F. Jiang, "New adaptive scheme for dynamic voltage restorer to voltage sag com-pensation and flexible self-recovery," in 2018 IEEE International Power Electronics and Application Conference and Exposition (PEAC), Shenzhen, China, 2018, pp. 1-6.

[6] Z. Sizhan, J. Liu, L. Zhou, Y. Zhu, and Xu Y. "Sag detection algorithm for dynamic voltage restorer used in wind farms under unbalanced and distorted grid voltage conditions," 2013 IEEE ECCE Asia Downunder, Australia, 2013, pp. 601-606.

[7] P. Li, L. Xie, J. Han, S. Pang, and P. Li. “ New decentralized control scheme for a dynamic voltage restorer based on the elliptical trajectory compensation," IEEE Transactions on Industrial Electronics, vol. 64, no. 8, pp. 6484-6495, Aug. 2017.

[8] F. Xiao, L. Dong, L. Li, and X. Liao, "Fast voltage detection method for grid-tied renewable energy generation systems under distorted grid voltage conditions", IET Power Electronics, vol. 10, no. 12, pp. 14871493, 2017

[9] G. Chen, L. Zhang, R. Wang, L. Zhang, and X. Cai, "A novel sPLL and voltage sag detection basedon LES filters and improved instantaneous symmetrical components method," IEEE Transactions on Power Delivery, vol. 30, no. 3, pp. 1177-1189, Mar. 2015.

[10] J. Wang, Y. Xing, T. Yang, and H. Wu, "A novel dual-DC-port dynamic voltage restorer with reduced-rating integrated DC-DC converter for wide-range voltage sag compensation," IEEE Transactions on Power Electronics, DOI: 10.1109/TPEL.2018.2882534.

[11] D. Mahinda Vilathgamuwa, H. M. Wijekoon and S. S. Choi, "A novel technique to compensate voltage sags in multiline distribution systemthe interline dynamic voltage restorer," IEEE Transactions on Industrial Electronics, vol. 53, no. 5, pp. 1603-1611, Oct. 2006.

[12] A. Khoshkbar Sadigh and K. M. Smedley, "Review of voltage compensation methods in dynamic voltage restorer (DVR)," 2012 IEEE Power and Energy Society General Meeting, 2012, pp. 1-8.

[13] A. M. Gee, F. Robinson, and W. Yuan, "A superconducting magnetic energy storage-emulator/battery supported dynamic voltage restorer," IEEE Transactions on Energy Conversion, vol. 32, no. 1, pp. 55-62, Mar. 2017.

[14] T. Jimichi, H. Fujita, and H. Akagi, "Design and experimentation of a dynamic voltage restorer capable of significantly reducing an energystorage element," IEEE Transactions on Industry Applications, vol. 44, no. 3, pp. 817-823, May 2008.

[15] Y. Wang, A. Bagheri, M. H. J. Bollen, and X. Xiao, "Single-event characteristics for voltage dips in three-phase systems," IEEE Transactions on Power Delivery, vol. 232, no. 2, pp. 832-840, Apr. 2017.

[16] S. Biricik and H. Komurcugil, "Optimized sliding mode control to maximize existence region for single-phase dynamic voltage restorers," IEEE Transactions on Industrial Informatics, vol. 12, no. 4, pp. 14861497, Jul. 2016.

[17] J. G. Nielsen, M. Newman, H. Nielsen, and F. Blaabjerg, "Control and testing of a dynamic voltage restorer (DVR) at medium voltage level," IEEE Transactions on Power Electronics, vol. 19, no. 3, pp. 806-813, May 2004.

[18] M. Shahabadini and H. Iman-Eini, "Improving the performance of a cascaded h-bridge-based interline dynamic voltage restorer," IEEE Transactions on Power Delivery, vol. 31, no. 3, pp. 1160-1165, Jun. 2016.

[19] C. Ngai-man Ho, H. S. H. Chung, and K. T. K. Au, "Design and implementation of a fast dynamic control scheme for capacitor supported dynamic voltage restorers", IEEE Transactions on Power Electronics, vol. 23, no. 1, pp. 237-251, Jan. 2008

[20] S. S. H. Bukhari, S. A., and B. Kwon, "A sag compensator that eliminates the possibility of inrush current while powering transformer- 
coupled loads", IEEE Journal of Emerging and Selected Topics in Power Electronics, vol. 5, no. 2, pp. 891-900, Jun. 2017.

[21] C. Meyer, R. W. Doncker, Y. W. Li, and F. Blaabjerg, “Optimized control strategy for a medium-voltage DVR-theoretical investigations and experimental results," IEEE Transactions on Power Electronics, vol. 23, no. 6, pp. 2746-2754, Nov. 2008.

[22] A. M. Rauf and V. Khadkikar, "An enhanced voltage sag compensation scheme for dynamic voltage restorer," IEEE Transactions on Industrial Electronics, vol. 62, no. 5, pp. 2683-2691, May 2015.

[23] E. K. Kenneth Sng, S. S. Choi, and D. Mahinda Vilathgamuwa, "Analysis of series compensation and DC-link voltage controls of a transformer less self-charging dynamic voltage restorer," IEEE Transactions on Power Delivery, vol. 19, no. 3, pp. 1511-1518, Jul. 2004.

[24] H. Hafezi and R. Faranda, "Dynamic voltage conditioner, a new concept for smart low-voltage distribution system," IEEE Transactions on Power Electronics, DOI: 10.1109/TPEL.2017.2772845.

[25] Y. Liu, Y. Xu, X. Xiao, Y. Zhu, and C. Guo, "A stages compensation and control strategy for series power- quality regulator," IEEE Transactions on Power Delivery, vol. 25, no. 4, pp. 2807-2815, Oct. 2010.

[26] F. Jiang, C. Tu, Q. Guo, Z. Shuai, X. He, and J. He, "Dual-functional dynamic voltage restorer to limit fault current," IEEE Transactions on Industrial Electronics, vol. 66, no. 7, pp. 5300-5309, Jul. 2019.

[27] S. K. Dash and P. K. Ray, "Power quality improvement utilizing PV fed unified power quality based on UV-PI and PR-R controller," CPSS Transactions on Power Electronics and Applications, vol. 3, no. 3, pp. 243-254, Sep. 2018.

[28] A. M. Gee, F. Robinson, and W. Yuan. "A superconducting magnetic energy storage-emulator/battery supported dynamic voltage restorer," IEEE Transactions on Energy Conversion, vol. 32, no. 1, pp. 55-64, Mar. 2017.

[29] Z. Shuai, W. Huang, and C. Shen, "Characteristics and restraining method of fast transient inrush fault currents in synchronverters," IEEE Transactions on Industrial Electronics, vol. 64, no. 9, pp.7487-7497, Sep. 2017.

[30] S. R. Arya, R. Maurya, and T. A. Naidu, "Amplitude adaptive notch filter with optimized PI gains for mitigation of voltage based power quality problems," CPSS Transactions on Power Electronics and Applications, vol. 3, no. 4, pp. 313-323, Dec. 2018.

[31] H. Jafarian, N. Kim, and B. Parkhideh, "Decentralized control strategy for AC-stacked PV inverter architecture under grid background harmonics," IEEE Journal of Emerging and Selected Topics in Power Electronics, vol. 6, no. 1, pp. 84-94, Mar. 2018.

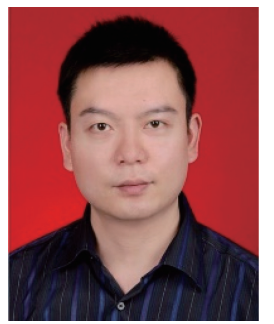

Chunming Tu received the M.S. and Ph.D. degrees in Electrical Engineering from Central South University, Changsha, China, in 2001 and 2003, respectively. He was with Hunan University, Changsha, as an Assistant Professor from 2004 to 2005, an Associate Professor from 2004 to 2009, and has been a Professor since 2009. His current research interests include power quality control and power electronics. His research interests mainly include power electronics, microgrid and power quality control. Dr. Tu has received the National Scientific and Technology Awards of China three times in 2018, 2010, and 2006, and the 2007 Scientific and Technological Awards from the National Mechanical Industry Association of China.

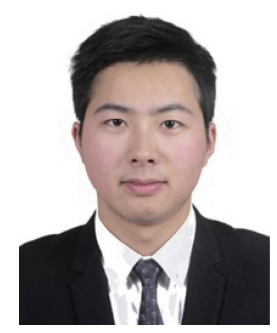

Qi Guo was born in Luan, Anhui, China, in 1993. He received the B.S. degree in College of Electrical Engineering, Anhui Polytechnic University, Wuhu, China, in 2014, and the M.S. degree from the College of Electrical and Information Engineering, Hunan University, Changsha, in 2016. Currently, he has been working toward the Ph.D. degree in Electrical Engineering from Hunan University, Changsha, China. His research interests include power electronics converter, distributed generation and power quality.

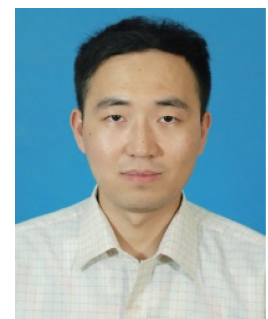

Fei Jiang received the B.S. and M.S. degrees in Electrical and Information Engineering from Changsha University of Science and Technology, Changsha, China, in 2007 and 2012, respectively, and received the Ph.D. degree in Electrical Engineering from the College of Electrical and Information Engineering, Hunan University, Changsha, China, in 2016. From 2007 to 2009, he was an Assistant Electrical Engineer at Northwest China Grid Co. Ltd., Xi' an, China. Since 2016, he has been a lecturer with Changsha University of Science and Technology, Changsha, China. His research interests include power electronics converter, distributed generation and power quality.

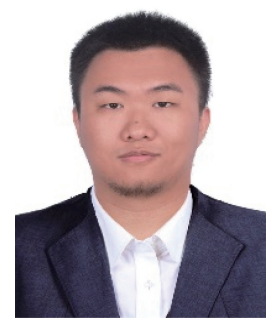

Cheng Chen was born in Beijing, China. He received the B.S. degree in Electrical Engineering and Automation in the Sichuan University, Chengdu, China, in 2017, and received the M.S. degree in Electric Power Engineering at KTH, Sweden, in 2019. Currently, he worked under the supervision of Prof. Math Bollen in a project funded Swedish Energy Agency. He did internships in Beijing branch companies in State Grid Corporation of China and interested in renewable energy integration and power system stability and control.

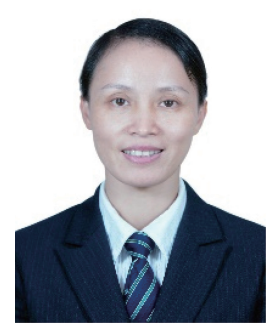

Xiaoyun Li was born in Jianyang, China. She received the B.S. degree in Electrical and Information Engineering from Tianjin University, Tianjin, China, in 1994, and received the M.S. degree in Electrical and Information Engineering from Fuzhou University, Fuzhou, China, in 2008. Currently, she is with the Nanping Power Supply Company of State Grid. Her research interests include distributed generation and power quality.

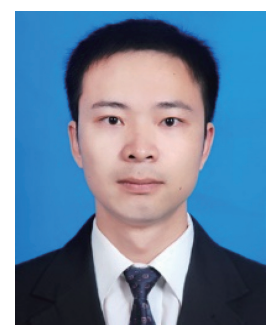

Fan Xiao was born in Hengyang, Hunan, China, in 1988. He received the B.S. degree from the College of Electrical and Information Engineering, Changsha University of Science and Technology, Changsha, China, and Hunan University, Changsha, in 2011, and the M.S. degree from the College of Electrical and Information engineering, Hunan University, in 2014. $\mathrm{He}$ is currently pursuing the Ph.D. degree with the College of Electrical and Information Engineering, Hunan University. His current research interests include harmonics suppression, solid-state transformers (SST), and dc SST.

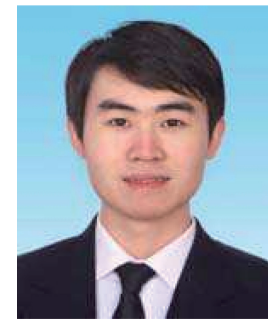

JiaYuan Gao was born in Henan, China, in 1991. He received his B.S. degree in Electrical Engineering from the Henan Polytechnic University, Henan, China, in 2015, and received the M.S. degrees in Shanghai University of Electric Power, Shanghai, China, in 2018. He is presently working towards his $\mathrm{Ph} . \mathrm{D}$. degree at the Electrical Engineering from the College of Electrical and Information Engineering, Hunan University, Changsha, China. His current research interests include grid-connected inverter control and the stability control of renewable energy power generation systems. 